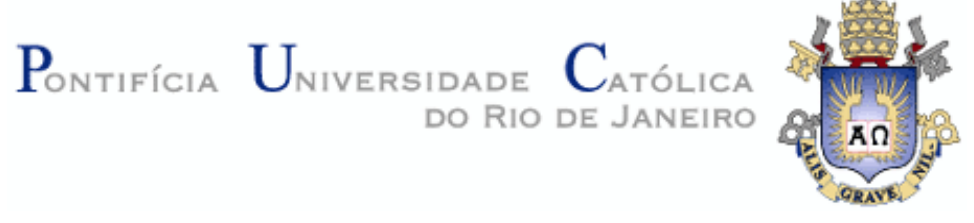

Carlos Roberto de Oliveira Charles

\title{
Manifestações do Espírito Libertador no \\ Continente da Esperança Uma perspectiva de José Comblin
}

Dissertação de Mestrado

Dissertação apresentada ao Programa de Pósgraduação em Teologia da PUC-Rio como requisito parcial para obtenção do título de Mestre em Teologia.

Orientadora: Prof ${ }^{a}$. Jenura Clothilde Boff

Rio de Janeiro Março de 2011 
Pontifícia U UIVERsidade Católica $_{\text {a }}$ DO RIO DE JANEIRO

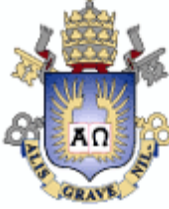

Carlos Roberto de Oliveira Charles

\title{
Manifestações do Espírito Libertador no Continente da Esperança Uma perspectiva de José Comblin
}

Dissertação apresentada como requisito parcial para obtenção do grau de Mestre pelo programa de Pós-graduação em Teologia da PUC-Rio.

\author{
Prof ${ }^{a}$. Jenura Clothilde Boff \\ Orientadora \\ Departamento de Teologia - PUC-Rio \\ Profa. Tereza Cavalcanti \\ Departamento de Teologia PUC-Rio
}

Prof. João Justino de Medeiros Silva Centro de Ensino Superior de Juiz de Fora Instituto Teológico Arquidiocesano

Profa Denise Berruezo Portinari Coordenadora Setorial de Pós-Graduação e Pesquisa do Centro de Teologia e Ciências Humanas - PUC-Rio

Rio de Janeiro, 21 de Março de 2011 
Todos os direitos reservados. É proibida a reprodução total ou parcial do trabalho sem autorização da universidade, do autor e do orientador.

\section{Carlos Roberto de Oliveira Charles}

É Frade da Ordem dos Frades Menores Conventuais e Ministro Ordenado. Graduou-se em Filosofia pela FSB/RJ (Faculdade São Bento do Rio de Janeiro) em 1995. Participou do Projeto de Pesquisa do PIBIC/CNPq em 1996 e 1997, durante a Graduação de Teologia pela PUC/RJ (Pontifícia Universidade Católica do Rio de Janeiro), com o Projeto "Os anjos na devoção popular". Graduou-se em Teologia na mesma Universidade, PUC/RJ em 1999. Pós-Graduou-se em História da Igreja (Lato Sensu) pela FSB/RJ em 2008. Tem Curso (incompleto) de Letras pela UFJF (Universidade Federal de Juiz de Fora). Atualmente participa, em nível de América Latina, do Ministério de Reflexão da FALC (Federação Latino Americana dos Conventuais).

Ficha Catalográfica

Charles, Carlos Roberto de Oliveira

Manifestações do Espírito Libertador no Continente da Esperança: uma perspectiva de José Comblin / Carlos Roberto de Oliveira Charles; orientadora: Jenura Clothilde Boff. - 2011.

$155 \mathrm{f.:}--\mathrm{cm}$

Dissertação (Mestrado)-Pontifícia Universidade Católica do Rio de Janeiro, Departamento de Teologia, 2011.

Inclui bibliografia

1. Teologia - Teses. 2. Manifestação. 3. Espírito Santo. 4. Libertação. 5. Vida. 6. Esperança. 7. Ação. 8. Comunidade. 9. América-Latina. 10. José Comblin. I. Boff, Lina. II. Pontifícia Universidade Católica do Rio de Janeiro. Departamento de Teologia. III. Título. 
A minha mãe Célia Maria Teixeira Charles (in memoriam); ao grande teólogo, Pe. José Comblin, no alto de seus 87 anos, e a todas as Comunidades Eclesiais de Base do Continente da Esperança. 


\section{Agradecimentos}

A Deus, cuja força se manifesta como ação, como Espírito de vida e libertação e, por ter despertado em mim uma leitura teológica pertinente e condizente com a realidade que vivemos.

À minha orientadora Professora Lina Boff, pelo tempo, paciência, dedicação e estimulo para a realização deste trabalho.

Ao CAPES e à PUC-Rio, pelos auxílios concedidos, sem os quais este trabalho não poderia ter sido realizado.

Às amigas Maria Helena de Souza Lourenço, Maria Aparecida de Souza, Lilia Sertã Junqueira, incentivadoras e colaboradoras. A esta última, principalmente pela verificação lógica, gramatical e ortográfica.

Aos professores do Departamento de Teologia da PUC-Rio em especial aos professores Pe. Geraldo Dôndici e Tereza Cavalcanti que, respectivamente, através de suas aulas e exemplo, instigaram-me a percorrer este caminho da esperança latente nas camadas empobrecidas do nosso Povo.

Ao amigo e primo Sandro Athayde Coelho pela incansável colaboração na formatação e nos auxílios de informática.

Aos demais amigos que de alguma forma contribuíram para a elaboração deste trabalho, seja indicando bibliografia ou criticando as idéias postas no papel.

Aos amados irmãos da minha Comunidade Religiosa da Custódia Imaculada Conceição do Rio de Janeiro (OFMConv.) pelo o incentivo. 


\section{Resumo}

Charles, Carlos Roberto de Oliveira; Boff, Jenura Clothilde. Manifestações do Espírito Libertador no Continente da Esperança: uma perspectiva de José Comblin. Rio de Janeiro, 2011. 155p. Dissertação de Mestrado Departamento de Teologia, Pontifícia Universidade Católica do Rio de Janeiro.

Diversas são as manifestações do Espírito Santo nas pessoas, no mundo, na história e na Igreja. Na América Latina, em meio a uma realidade de opressão/dominação, vida/morte, o Espírito de Deus se manifesta na forma da ação transformadora, libertando, produzindo vida e a conduzindo para sua plenitude. Neste contexto eclesial, as pequenas comunidades suscitadas pelo Espírito nutrem a esperança de um porvir diferente, feliz e realizado, já presente nos sinais da experiência que fazem de Deus. O presente trabalho acadêmico pretende demonstrar esta manifestação do Pneuma Divino que age, liberta, desperta a palavra, forma comunidade e, por fim, gera vida nova. A perspectiva teológica de José Comblin abre possibilidades de reflexão para esta manifestação libertadora do Espírito Santo, iluminando uma prática eclesial comprometida com o amor e a justiça, configuração de uma nova espiritualidade marcada pela vida solidária, pela fé partilhada e pela esperança consolidada.

\section{Palavras-Chave}

Manifestação; Espírito Santo; Libertação; Vida; Esperança; Comunidade; Ação; América Latina; José Comblin. 


\section{Résumé}

Charles, Carlos Roberto de Oliveira; Boff, Jenura Clothilde (Directeurs). Des manifestations de L'Esprit libérateur dans le continent de l'espérance: une perspective de José Comblin. Rio de Janeiro, 2011, 155p. Dissertation de maîtrise - Departamento de Teologia, Pontifícia Universidade Católica do Rio de Janeiro

Il y a plusieurs manifestatations de l'Esprit Saint dans les personnes, dans le monde, dans l'histoire et dans l'Eglise. Dans l'Amérique Latine au milieu d'une réalité d'oppression/domination, vie/mort, L'Esprit de Dieu se manifeste dans la forme de l'action renouvellée, en libérant, en produisant vie et en la conduisant vers sa plenitude. Dans ce contexte ecclésiale les petites communautés créées par l'Esprit nourrissent l'espérance d'un avenir différent, heureux et réalisé, déjà présenté dans les signes de l'expérience qu'elles font de Dieu. Le travail académique a l'intention de démontrer cette manifestation du Pneuma Divine qui agit, libère, réveille le mot, crée une communauté, et enfin, crée une nouvelle vie. La perspective théologique de José Comblin ouvre des possibilités de réflexion pour cette manifestation libératrice de l'Esprit Saint, en illuminant une pratique ecclésiale qui a un compromis avec l'amour et la justice, une configuration d'une nouvelle spriritualité, marquée par la vie solidaire, para la foi partagée et par l'espérance consolidée.

\section{Mots-clés}

Manifestation; Esprit Saint; Libération; Vie; Espérance; Communauté; Action; Amérique Latine; José Comblin. 


\section{Sumário}

1. Introdução 12

2. Experiência de vida no Espírito Santo 15

2.1. Introdução 15

2.2. Experiência da força pneumática na vida dos 18 empobrecidos

2.2.1. A Teologia da Libertação: experiência fundante 20

2.2.2. A perspectiva do pobre: nova experiência teológica 23

2.2.3. A ação do Pneuma Divino nos pobres 28

2.3. Espiritualidade da libertação 36

2.3.1. Na Teologia da Libertação: experiência de uma nova espiritualidade 41

2.3.2. Espiritualidade a partir do pobre 44

2.3.3. Frutos da ação libertadora do Pneuma Divino 46

2.4. Ação missionária do Pneuma Divino nas comunidades de fé $\quad 48$

2.4.1. Pneuma Divino e Igreja: missão na perspectiva da TdL 48

2.4.2. Igreja e missão a partir dos pobres 51

2.4.3 A ação pneumático-missionária das CEBs 53

2.5. Conclusão parcial 56

3. O Espírito de vida na reflexão de fé 59

3.1. Introdução 59

3.2. O conceito teológico de Pneuma Divino nas Escrituras 60

3.2.1. No Antigo Testamento: sopro de vida 61

3.2.2. No Novo Testamento: vida segundo o Espírito 65

3.2.3. Focos divergentes do Pneuma Divino nos dois Testamentos 69

3.3. O Pneuma Divino como manifestação de vida na compreensão teológica $\quad 70$

3.3.1. O Espírito de Vida na pneumatologia de Yves Congar 78

3.3.2. "O Espírito da Vida" na pneumatologia de Jürgen Moltmann

3.3.3. A conceituação de Espírito de Vida na ótica de Comblin 83

3.4. A manifestação do Pneuma Divino na vida do mundo 92

3.4.1. As "Duas Mãos" do Pai 92

3.4.2. Presença e missão do Pneuma Divino no mundo 97

3.4.3. O Pneuma Divino e a libertação 100

3.5. Conclusão parcial 103

4. Sinais que apontam Vida Plena no Espírito Santo 105

4.1. Introdução 105 
4.2. Sinais escatológicos da ação pneumática 107

4.2.1. O "já" e o "ainda não" do Reino de Deus nas CEBs 107

4.2.2. A esperança dos pobres vive 112

4.2.3. Nova Criação no Espírito Santo 116

4.3. A primazia da vida sobre a morte: transformação pelo Pneuma Divino

4.3.1. O contexto de morte no Continente Latino-americano: contra-sinal à vida no Pneuma Divino

4.3.2. Sinais da força da vida na América Latina 125

4.3.3. A transformação no Espírito Santo 132

4.4. Eternidade feliz: condução do Pneuma Divino, da libertação à Vida

4.4.1. Sinais de esperança na Teologia da Libertação 136

4.4.2. O Espírito Libertador aponta para a eternidade 138

4.4.3. Manifestação de esperança do Pneuma Divino: implicações pastorais

4.5. Conclusão parcial

5. Conclusão 145

6. Referência bibliográfica 148

6.1. Bibliografia do autor 148

6.2. Bibliografia utilizada 149

6.3 Bibliografia consultada 154 


\section{Lista de Siglas}

ANF - The Ante-Nicene Fathers: Translations of the writings of the fathers down to A.D. 325, org. Alexandre Roberts e James Donaldson (Grand Rapids, Eerdmans, [1965]-[1968]

AT - Antigo Testamento

CEBs - Comunidades Eclesiais de Base

DAp - Documento de Aparecida

DM - Documento de Medellín

DP - Documento de Puebla

DS - Denzinger

DSD - Documento de Santo Domingo

$\mathrm{EC}-1^{\mathrm{o}}$ Intereclesial das Cebs

FC - Fathers of the Church: Second Series (Washington, D.C., Catholic University of America Press)

IPLA - Instituto de Pastoral Latino-Americano

JOC - Juventude Operária Católica

LG - Lumen Gentium

NT - Novo Testamento

PB - Pernambuco

PG - Patrologiae cursus completus: Series Graeca, org. J.-P. Migne, 161, vols. (Paris, J.-P. Migne, 1857-1866)

TdL - Teologia da Libertação

SC - Sources Chrétiennes (Paris, Éditions du Cerf) 
Ser cristão é viver segundo o Espírito de Jesus e está na base da espiritualidade que não consiste em doutrinas, mas em experiências vividas à luz da experiência espiritual de Jesus.

Leonardo Boff 